\title{
The impact of global scientific and education policy on the staffing of innovative breakthrough
}

\author{
Valeriia Semenova ${ }^{1}$ and Mikhail Fridman ${ }^{2, *}$ \\ ${ }^{1}$ Non-state private educational institution of higher education «Moscow Economic Institute», 109390, \\ Artyukhinoy str., 6 build. 1, Moscow, Russia \\ ${ }^{2}$ The Russian Presidential Academy of National Economy and Public Administration, 119571, \\ Prospect Vernadskogo, 82, build. 1, Moscow, Russia
}

\begin{abstract}
This article is devoted to an important and topical scientific problem of personnel support for innovative breakthrough in the context of globalization. Much attention is paid to understanding the role of global scientific and educational policy as a conceptual and methodological basis for long-term development. The purpose of the article is to analyze the problem, identify the causes and possible consequences of the personnel crisis, determine and justify the role of global scientific and educational policy in achieving an innovative breakthrough. The article is based on research conducted on the basis of observation, analysis, generalization and systematization of scientific literature, expert assessments, regulatory documents and public statements of officials. The work is structured, which is confirmed by the use of traditional logic and methodology of scientific research methods (analysis, synthesis and extrapolation). The article reflects the results of studying the theoretical and methodological justification of the global scientific and educational policy and the conditions of its impact on the staffing of an innovative breakthrough.
\end{abstract}

\section{Introduction}

At present, against the backdrop of the unfolding sixth technological paradigm, the formation of a multipolar world with the simultaneous development of several centers of political power and international trade leads humanity to realize the need to radically change the individual and collective consciousness. Globalization, digitalization and optimization are the fundamental vectors of the formation of the information society and the knowledge economy [1].

A wide range of domestic and foreign scientists paid much attention to this problem, including Daniel Bell, Brzezinski Z., Baudrillard J., Glazyev S. Yu., Zinoviev A. A., Manuel Castells, Lvov D. S., Makhloup F., Jose Ortega y Gasset, Stonier T., Toffler, A., Habermas Y., Spengler O, Jaspers K., Masuda Y., and others.

Theoretical and information base of the research was formed by works devoted to the development of information society, knowledge economy, sixth technological paradigm,

\footnotetext{
${ }^{*}$ Corresponding author: mffree79@mail.ru
} 
globalization and scientific and educational policy. Based on the materials of Russian and foreign researchers, we have modeled the optimal conditions for an innovative breakthrough in the context of its staffing based on the modernization of conceptual and methodological approaches to scientific and educational policy, taking into account the spread of globalization as a prevailing trend that radically changes consciousness through the transition to a new technological paradigm. The purpose of the research is to analyze the current state and prevailing trends of personnel support for innovative breakthrough in the context of the development of global scientific and educational policy. In this article, an innovative breakthrough is understood as a transition from a less productive technological paradigm to a more productive one. From our point of view, personnel support for an innovative breakthrough is a set of measures that includes analysis of personnel needs, professional selection, evaluation, training, development, adaptation, consolidation and movement of personnel in accordance with the technical, technological and economic requirements of our time. In our opinion, the global scientific and educational policy is a set of strategic solutions to global problems of our time by means of science and education in the context of the development of international integration.

\section{Materials and methods}

The sixth technological paradigm is focused on the development of high-tech sectors of the economy, on flexible production automation, space technologies, production of structural materials with predetermined properties, nuclear industry and energy, air transportation, alternative energy sources and environmentally friendly industry. The transition to the sixth technological paradigm is associated with the wide spread and improvement of robotics, biotechnology, based on breakthrough in molecular biology and genetic engineering, nanotechnology, artificial intelligence, global information networks and integrated highspeed transport systems.

It is obvious that a state capable of making an innovation breakthrough in the conditions of the sixth technological paradigm will be able to claim a leading position in the world community by setting strategic guidelines and priority directions of social and economic development [2].

In our opinion, three components are required to achieve this goal, including the goal (the goal of an innovative breakthrough is a strategic vision of the expected result of the transformation of the system of social relations in the course of changing the mode of production), the innovative solution (a means of innovative breakthrough due to reaching a qualitatively higher level of production efficiency) and strategic management (a means of innovative breakthrough, which includes the whole range of actions from conception to obtaining long-term policies).

The fourth industrial revolution is associated with the blurring of the boundaries between physical, digital and biological technologies, including artificial intelligence, Internet of things, unmanned transport, 3D printing, nanotechnology, biotechnology, quantum computers; NBIC convergence intensification; the development of "smart" production; work with big data. It should also be noted that the key problem in determining the goals, means and ways of innovative breakthrough is personnel [4].

All these and many other trends in the modernization of high-tech sectors of the economy have led to a radical revision of the format and conditions of the innovation breakthrough, which requires a fundamental change in the approaches to personnel policy $[5]$.

Over the past 20 years, representatives of almost all strategically important sectors of the national economy have declared an acute shortage of personnel, while every year the 
problem does not lose its relevance. According to a large number of publications, the defense industry, energy, agriculture, healthcare, education, various sectors of industry, etc. have a large shortage of managers, engineers, technicians and workers. [6]

According to McKinsey Global Institute experts, the global human resources crisis is gaining momentum and today there is a noticeable shortage of about 40 million highly qualified specialists in the world, which, according to experts, slows down the pace of economic growth. Analysis of the state of the labour market in 70 countries, which account for $96 \%$ of world GDP and $87 \%$ of the world population, showed that by 2030 , the number of people employed in the world economy will grow to 3.5 billion. However, in 2020, the world will feel an acute demand for high-class specialists with a good education. From the point of view of analysts, representatives of engineering specialties, in particular in the sphere of aerospace production, will be the most lacking in the world. Experts state that China, with its fast-growing economy, will suffer the most from the shortage of personnel (universities will not be able to meet the demand for specialists), European countries, Japan, and the United States will also suffer (but the main reason will be the demographic situation). Today we can state that humanity is experiencing a crisis of unprecedented scale - a crisis of goals and results, processes and resources, science and education. It's a crisis of thinking.

Generations X, Y and Z are very different. Above all, these differences affect their relationship to themselves, to others, to society as a whole, to work and to their own destiny. If generation $X$ caught the Soviet Union time and its obsession with building communism, which requires working together on a common goal, then generation $\mathrm{Y}$ and $\mathrm{Z}$ are completely devoid of understanding this need, they are individualistic. Consumer society as a naturally occurring phase after the mass development of technologies and industries in the twentieth century led to a sharp increase in helplessness and infantilism in the younger generation. Undoubtedly, today's young people are well versed in modern technologies and their technological skills are amazing, but the social and humanitarian sphere of their worldview development is far behind the ideas of previous generations. Young people know a lot about their rights and have a keen sense of justice, but often do not know and cannot defend their interests in socially acceptable forms [7].

Education has deteriorated significantly. Children often get into primary school without proper selection. It is very important to select by abilities at the very beginning of learning, otherwise, when the "strong" and the "weak" are combined, everyone, even teachers, loses their motivation. "Strong" students are not interested in going through one topic for a long time, "weak" students are not interested in rushing too much, and the primary school teacher needs to focus either on those or on other students. There is no other way $[8,9]$.

High school is also a waste of time, because it is completely focused on passing the final exams. It doesn't make any sense. Children are trained to pass meaningless exams, which often determine the success of almost all of their life. To pass exams well, you need to have a good memory. There is an opinion that one of the signs of genius is absentmindedness associated with switching attention from operational tasks to strategic ones. It turns out that in a yard of cases a genius has to remain a " $C$ " student $[10,11]$.

Vocational school is still in a very difficult situation. Since 2013, elementary vocational education in Russia has been eliminated as a level of education. Everyone studies in technical schools and colleges: both those who work and those who should lead them. Most graduates do not go to work in their specialty when they finish secondary vocational education. It remains a social protection instrument for adolescents in difficult circumstances, rather than a driving force for the economy and production.

Additional education continues to increase the focus towards Amateur art, leaving technical creativity aside. Quantoriums created for children are more like a game than a tool for intensive development of engineering thinking [12,13]. 
Higher education, which has mostly switched to bachelor's degree, has taken a focus on the transfer of culture, rather than on the professional training of future specialists and managers $[14,15]$.

\section{Results}

The question naturally arises: Where can Russia get qualified personnel capable of providing it with an innovative breakthrough in the high-tech economy if neither school, college nor university are engaged in this purposefully?

An innovative breakthrough is not only the subject of ambitions and claims of a single state, it is an objective necessity that arises in the course of overcoming the growing global problems of our time, affecting the future of all mankind, the solution of which requires the unification of efforts of the entire globe. This is especially true in the absence of technical guarantees to prevent these risks.

Today we are forced to state that despite the triumph of the current engineering advances, modern technologies are often unable to confidently withstand the outlined threats, the expectations from science and education therefore call for a fundamental review of the content and format of international relations and the domestic policies of states with regard to this aspect.

In this context, we assign a special role to scientific and educational policy, which is designed to define, formulate and defend priorities for the strategic development of the intellectual potential of the planet, aimed at the formation of appropriate knowledge, relationships and competencies.

We believe that in the current circumstances there should be a single global scientific and educational policy aimed at preparing mankind to solve common world problems. This task is universal, i.e. each country, each community and each individual should be fully aware of their own and common responsibilities, as well as the degree of participation in the solution of the present problem. At the same time, it is not only about the moral and psychological qualities and attitudes of the individual, but also the professional consciousness that produces the relevant innovative political, legal, economic and technological solutions.

Considering the choice of conceptual grounds for the formation of a global scientific and educational policy as a fundamental political and economic problem in the context of the deployment of a cultural and historical paradigm of the information society, the formation of a digital economy, the harmonization of international relations, the optimization of global and regional development, focused on the creation of a constructive dialogue between the subjects of preparation and adoption of appropriate political decisions, it should be noted that the above approach allows the following.

\section{Discussions}

The problem of reforming science and education has existed for a long time and is not a surprise to anyone. Globalization, informatization, digitalization of society, transition to the knowledge economy, emergence and deployment of such international alliances and organizations as BRICS, EurAsEC, SCO, etc., the growing information and economic confrontation in the world - these circumstances are among the first, in our opinion, determine the need for a fundamental review of the strategic guidelines and priorities for modernization of education and science, both in the internal policy of the state and in the foreign and global level, too. 
The analysis of external challenges, international trends and dominant trends of the state scientific and educational policy, the study of public statements of the leadership of developed and developing countries, regulatory documents, data of the world statistics, as well as the study of the experience of international leaders and best domestic practices allows to identify and generalize the fundamental problems, difficulties and barriers that hinder the deployment of a new paradigm of global scientific and educational policy of the information society, capable of solving those problems.

One of the most important problems facing the society today is the study of existing problems and the political and economic substantiation of the development of new conceptual approaches to the formation and implementation of methodological principles of global scientific and educational policy aimed at the formation and development of the next cultural and historical paradigm - the information society in a globalized strategic management.

\section{Conclusion}

In our opinion, the most important role in building the information society and overcoming the global problems of our time is played by the global scientific and educational policy, which in this article is understood as the development, implementation and promotion of a system of political measures aimed at the development of society by means of education and science. This suggests that the choice of the conceptual foundations of the new methodology, which is the political economy problem of formation and deployment of the information society, based on the development of effective approaches to managing the strategic development of intellectual potential of human civilization in terms of natural change of the cultural-historical paradigm. This is especially relevant in the context of the progressive crisis of the Humanities, which is expressed, first of all, in a multipolar, uncertain attitude to man as a subject of knowledge in the absence of established axiomatics, conceptual system, methodological apparatus and criteria for assessing reliability.

From our point of view, the prerequisites and conditions for the emergence of a new paradigm and methodology of scientific and educational policy are largely related to the need to overcome the crisis of the modern university, which opens up completely different perspectives, allowing it to be considered as a special environment-forming platform with high scientific, educational, industrial, cultural, political, economic, technological and environmental impact. These prerequisites obviously include the following: reluctance of the university to give up academic autonomy, inability of the state to provide parity, symbiotic conditions of strategic interaction with the academic community, devaluation of the value of higher education in the consumer society against the background of a deep crisis of social management, formation of a new type of intellectual elite in all spheres of activity. Against the background of changing cultural and historical paradigm in the transition from an agrarian and industrial society to an information society, these circumstances largely determine the radical change in the relationship between the state and the University, as shown in the figure below. 


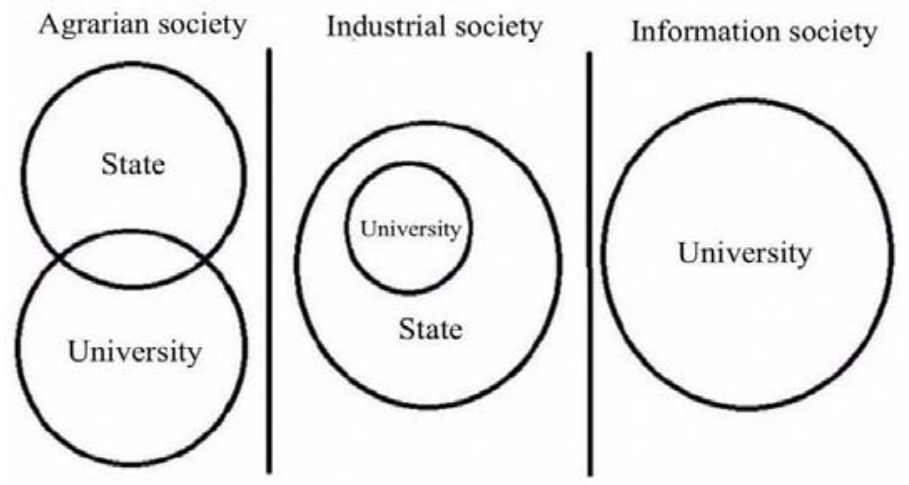

Fig. 1. Changes in the relationship between the state and the university

In conclusion, we would like to note that staffing for an innovative breakthrough requires strengthening: general education school in terms of forming a holistic worldview, scientific picture of the world and key social skills, qualities and characteristics (independence, cognitive motivation, flexibility, etc.); professional school in terms of developing professional consciousness and improving the efficiency of social and labour adaptation; higher education in strategic thinking on a national and global scale; additional education in the development of technical and artistic creation abilities. It's very important to come to an agreement, i.e. the subjects of the internal state scientific and educational policy (science, education, business, government, family, etc.) must develop a consensus on the goals, content, principles, methods and resources of scientific and educational reform. Subjects of the global scientific and educational policy (states, universities, transnational corporations, etc.) should also be ready to hear each other, otherwise the circumstances that threaten the further existence of mankind will not be leveled.

\section{References}

1. E. Ubushiev, Economic security in various technological modes. Theoretical and Applied Economics, 3, 1 - 21 (2018) DOI: 10.25136/2409-8647.2018.3.27119

2. E. Ubushiev, Economic security in various technological modes. Theoretical and Applied Economics, 3, 1 - 21 (2018) DOI: 10.25136/2409-8647.2018.3.27119 URL: https://en.nbpublish.com/library read article.php?id=27119 (Last accessed 16.06.2020)

3. Leadership Council of the Sustainable Development Solutions Network Indicators and a Monitoring Framework for the Sustainable Development Goals. Launching a data revolution for the SDGs (New York, 2015)

4. C. B. Frey, M. A. Osborne, "The future of employment: How susceptible are jobs to computerisation?," Technological Forecasting and Social Change, Elsevier, 114(C), 254-280 (2017) DOI: 10.1016/j.techfore.2016.08.019

5. A. Kalinina, Russia 4.0: How to prepare the country for the Fourth Industrial Revolution https://www.rbc.ru/opinions/economics/13/01/2017/5878d2389a79470077130332 (Last accessed 16.06.2020) 
6. H. David, "Why Are There Still So Many Jobs? The History and Future of Workplace Automation." Journal of Economic Perspectives, 29(3), 3-30 (2015). DOI: 10.1257/jep.29.3.3

7. H. David, D. Dorn, "The Growth of Low-Skill Service Jobs and the Polarization of the US Labor Market." American Economic Review, 103(5), 1553-1597 (2013) DOI: 10.1257/aer.103.5.155

8. S. Masino, M. Niño-Zarazúa, What works to improve the quality of student learning in developing countries? Int. J. Educ. Dev., 48(C), 53-65 (2016) DOI: 10.1016/j.ijedudev.2015.11.012

9. K. Birchler, K. Michaelowa, Making aid work for education in developing countries: an analysis of aid effectiveness for primary education coverage and quality Int. J. Educ. Dev, 48(C), 37-52 (2016) DOI: 10.1016/j.ijedudev.2015.11.008

10. S. Jones, How does classroom composition affect learning outcomes in Ugandan primary schools? Int. J. Educ. Dev., Elsevier, 48(C), 66-78 (2016) DOI: 10.1016/j.ijedudev.2015.11.010

11. E. Hanushek, L. Woessmann, Do better schools lead to more growth? Cognitive skills, economic outcomes, and causation J. Econ. Growth, 17(4), 267-321 (2012) DOI 10.1007/s10887-012-9081-x

12. A. Riddell, M. Niño-Zarazúa, The effectiveness of foreign aid to education: what can be learned? Int. J. Educ. Dev., 48(C), 23-36 (2016) DOI: 10.1016/j.ijedudev.2015.11.013

13. T. Addison, M. Niño-Zarazúa, F. Tarp, Aid, social policy and development J. Int. Dev., 27(8), 1351-1365 (2015) DOI: 10.1002/jid.3187

14. UNESCO Teaching and Learning: Achieving Quality for All. Education for All Global Monitoring Report UNESCO (Paris, 2014)

15. S. P. Heyneman, B. Lee, International organizations and the future of education assistance Int. J. Educ. Dev., 48, 9-22 (2016) DOI: 10. 1016/ j. ijedudev. 2015. 11. 009

16. K. Pyhältö, L. McAlpine, J. Peltonen, M. Castello, How does social support contribute to engaging Post-PhD experience? European Journal of Higher Education, 17(4) (2017). DOI: 10.1080/21568235.2017.1348239 